\title{
Anthropometric Evaluation of Pterion in Dry Human Skulls Found in Southern India
}

\author{
Pretty Rathnakar ${ }^{1}$, Remya Vinod ${ }^{2}$, Swathi $^{3}$, Anuja Sinha ${ }^{4}$
}

\author{
${ }^{1}$ Associate Professor, Department of Anatomy, K. S. Hegde Medical Academy, Mangalore, Karnataka, India. \\ ${ }^{2}$ Lecturer, Department of Anatomy, K. S. Hegde Medical Academy, Mangalore, Karnataka, India. \\ ${ }^{3}$ Associate Professor, Department of Anatomy, K. S. Hegde Medical Academy, Mangalore, Karnataka, India. \\ ${ }^{4}$ Assistant Professor, Department of Anatomy, K. S. Hegde Medical Academy, Mangalore, Karnataka, India.
}

\section{ABSTRACT}

\section{BACKGROUND}

Pterion is a H- shaped sutural convergence seen in the Norma Lateralis of skull. After 2-3 months of birth, the anterolateral fontanelle in the neonatal skulls close to form the pterion. It is the meeting point of four bones sphenoid, parietal, temporal and frontal. Four types have been noted-spheno-parietal, fronto-temporal, epipteric and stellate. Pterional approach is commonly undertaken in surgical management of tumours involving inferior aspects of frontal lobe, like olfactory meningiomas, orbital, retro-orbital, sellar, chiasmatic, subfrontal, prepontine areas, anterior circulation and basilar artery aneurysm. The knowledge regarding the various shapes and distances from different points to pterion (distance of centre of pterion was calculated from mid-point of superior margin of zygomatic arch (PZA), Frontozygomatic suture (PFZ), tip of the mastoid process (PMP), and anterosuperior margin of external acoustic meatus (PEAM)) is useful for treating number of pathologies in brain. So, this is also useful for neurosurgeons, anatomists, anthropologists and forensic medicine specialists. In the present study, we have attempted to classify the type of pterion and calculated the distance of centre of pterion from various landmarks and compared the measurements on the right and left side.

\section{METHODS}

This study was conducted in the Department of Anatomy, K. S. Hegde Medical Academy, Mangalore. 50 dry human skulls of unknown sex were obtained from the Department of Anatomy and studied. The pterion was observed and classified according to the articulation of bones and the distance of centre of pterion was calculated from mid-point of superior margin of zygomatic arch (PZA), Frontozygomatic suture (PFZ), tip of the mastoid process (PMP), and anterosuperior margin of external acoustic meatus (PEAM).

\section{RESULTS}

The sphenoparietal variety was the commonest (72\%) followed by fronto temporal $(18 \%)$ and the least common was epipteric (2\%). On comparison of measurements of right and left sides, distance of centre of pterion from mid-point of superior margin of zygomatic arch (PZA), Frontozygomatic suture (PFZ), tip of the mastoid process (PMP), and anterosuperior margin of external acoustic meatus (PEAM) did not show any significant difference.

\section{CONCLUSIONS}

Knowledge of position of pterion from various landmarks is very important for neurosurgeons as there is a chance of injury to vital structures present beneath the pterion. The knowledge of position of pterion from various landmarks is very important for neurosurgeons as there is a chance of injury to vital structures present beneath pterion. This study is aimed at South Indian population and can be conducted among other populations.

\section{KEY WORDS}

Pterion, Spheno-Parietal, Fronto-Temporal, Epipteric and Stellate
Corresponding Author:

Remya Vinod,

Department of Anatomy,

K. S. Hegde Medical Academy,

Deralakatte, Mangalore-575018,

Karnataka, India.

E-mail: remyavinod35@gmail.com

DOI: $10.14260 / \mathrm{jemds} / 2019 / 541$

Financial or Other Competing Interests: None.

How to Cite This Article:

Rathnakar P, Vinod R, Swathi, et al. Anthropometric evaluation of pterion in dry human skulls found in Southern India. J. Evolution Med. Dent. Sci. 2019;8(31): 24852488, DOI: $10.14260 /$ jemds/2019/541

Submission 14-06-2019,

Peer Review 20-07-2019,

Acceptance 27-07-2019,

Published 05-08-2019. 


\section{BACKGROUND}

Parietal bone near its antero-inferior angle forms a ' $\mathrm{H}$ ' shaped arrangement. Four bones, the parietal, frontal, greater wing of sphenoid and the squamous part of temporal meet here. A circle drawn here encloses all these bones and is called, the pterion. 'Pterion' in Greek means 'wing'.[1] It lies $4 \mathrm{~cm}$ above the zygomatic arch and $3.5 \mathrm{~cm}$ behind the fronto-zygomatic suture. Anterior branch of middle meningeal artery and Sylvian point of the brain lies beneath it. It is of surgical importance for positioning of burr - holes to evacuate extradural haematomas. It also corresponds to the anterolateral fontanelle of the neonatal skull. Motor speech area of Broca's and insula is situated here.[2]

Intradural pterional approach is used as surgical approach to optic nerve sheath meningioma, whereas extradural pterional approach for optic nerve decompressions as well as for tumour resections and biopsies.[3] For the Surgical management of tumours involving inferior aspects of frontal lobe, like olfactory meningiomas, retro-orbital sellar, chiasmatic, subfrontal, prepontine areas, anterior circulation and basilar artery aneurysm this approach is useful.[4] Pterional approach is useful in performing surgeries with minimal tissue injury without compromising surgical results. According to Broca there are three types of pterion sphenoparietal, frontotemporal and stellate. ${ }^{[5]}$

Pterion was classified by Murphy et al[6] into four types

a) Spheno-Parietal (SP): here the greater wing of sphenoid articulates with the parietal bone

b) Fronto-Temporal (FT): here the squamous part of temporal bone articulates with frontal bone

c) Stellate: here all the bones articulate at one point

d) Epipteric: here there is a wormian bone present between all the bones.

Two more variety of pterion zygomatico-parietal type and zygomatico temporal types were observed in study by Wang et al. [7]

In the present study we have attempted to classify the pterion based on Murphy's classification and to calculate the distance of centre of pterion from various landmarks [Table 2].

\section{Aims and Objectives}

In the present study we have attempted to classify the type of pterion and calculated the distance of centre of pterion from various landmarks and compared the measurements on the right and left side.

\section{METHODS}

50 dry human skulls of unknown sex were studied obtained from the Department of Anatomy. The pterion was observed and classified according to the articulation of bones and the distance of centre of pterion was calculated from mid-point of superior margin of zygomatic arch (PZA), Frontozygomatic suture (PFZ), tip of the mastoid process (PMP), and anterior superior margin of external acoustic meatus (PEAM). The measurement was done using Vernier callipers with an accuracy of $0.1 \mathrm{~mm}$. For measurement of centre of pterion perpendicular bisectors theorem was used. The suture coming in direct contact was utilised for taking measurements using geometric compass. To avoid bias three different measurements were taken and average was calculated.

\section{Statistical Analysis}

The result observed was tabulated based on types and their respective percentage was calculated. The distance of pterion to mid-point of zygomatic arch (PZA), frontozygomatic suture, tip of the mastoid process and external acoustic meatus were compared on right and left side. Shapiro Wilk test on SPSS was used to assess the normality distribution of the data, the median IQR values were taken into consideration and on obtaining skewed distribution on the data, accordingly Mann Whitney $U$ test was performed on the data to assess whether there is statistically ( $p$ Value of $<0.05$ ) significant difference in the readings of right and left side.

\section{RESULTS}

The sphenoparietal variety was the commonest (72\%) followed by fronto temporal (18\%) and least common was epipteric (2\%).

\section{Types of Pterion}

In the present study we found sphenoparietal to be the most common type $(72 \%)$. Percentage distribution of other types are as shown in Table no 1. Various types of pterion are shown in Figure 1. The measurements of centre of pterion to midpoint of zygomatic arch (PZA), frontozygomatic suture, tip of the mastoid process and external acoustic meatus on right and left side has been tabulated (Table 2). The various parameters when compared on right and left side did not differ significantly as shown in Table 2.

\begin{tabular}{|c|c|}
\hline Type of Pterion & n (\%) \\
\hline Spheno-parietal & $36(72)$ \\
\hline Fronto-temporal & $9(18)$ \\
\hline Stellate & $4(8)$ \\
\hline Epipteric & $1(2)$ \\
\hline Total & $\mathbf{5 0}(100)$ \\
\hline Table 1. Table Showing Distribution of The Types of Pterion \\
\hline
\end{tabular}

\begin{tabular}{|c|c|c|c|}
\hline Measurement & $\begin{array}{c}\text { Right (cm) } \\
\text { Median [IQR] }\end{array}$ & $\begin{array}{c}\text { Left (cm) } \\
\text { Median [IQR] }\end{array}$ & p Value \\
\hline PZA & $3.2[2.7-3.3]$ & $3.2[2.7-3.3]$ & 0.961 \\
\hline PFZ & $4.0[3.8-4.1]$ & $4.0[3.8-4.1]$ & 0.859 \\
\hline PMP & $8.3[8.0-8.5]$ & $8.3[8.1-8.5]$ & 0.959 \\
\hline PEAM & $5.6[5.4-5.8]$ & $5.6[5.4-5.7]$ & 0.853 \\
\hline
\end{tabular}

Table 2. Table Showing the Various Measurements From the Centre of the Pterion

$\mathrm{p}$ Value $<0.05$ - statistically significant- Mann Whitney U Test.

'PZA - distance of centre of Pterion to mid-point of superor margin of zygomatic arch, PFZ - Pterion to frotozygomatic suture, PMP- Pterion to tip of the mastoid process, PEAM- Pterion to superor margin of external acoustic meatus.

\begin{tabular}{|c|c|c|c|c|c|c|c|c|}
\hline \multirow{2}{*}{ Studies } & \multicolumn{2}{|c|}{ PZA (cm) } & \multicolumn{2}{|c|}{ PFZ (cm) } & \multicolumn{2}{|c|}{ PMP (cm) } & \multicolumn{2}{|c|}{ PEAM (cm) } \\
\hline & Right & Left & Right & Left & Right & Left & Right & Left \\
\hline $\begin{array}{c}\text { Mishra et al[ }{ }^{8]} \\
(\text { mean } \pm S D)\end{array}$ & 3.71 & 3.68 & 3.20 & 3.11 & 8.02 & 8.13 & 5.19 & 5.12 \\
\hline $\begin{array}{r}\text { Oguz et al[9] } \\
(\text { mean } \pm \text { SD) }\end{array}$ & 4.05 & 3.85 & 3.3 & 3.44 & - & - & - & - \\
\hline $\begin{array}{l}\text { Anjana et al }{ }^{[10]} \\
(\text { Mean } \pm \text { SD })\end{array}$ & 4 & 4 & 3 & 2.9 & - & - & - & - \\
\hline \begin{tabular}{|c|} 
Eboh and \\
Obaroefe (mean \\
\pm SD) \\
\end{tabular} & 4.022 & 3.952 & 3.206 & 3.108 & - & - & - & - \\
\hline $\begin{array}{c}\text { Sucharitha \& } \\
\text { Roshni }^{[11]}\end{array}$ & 3.783 & 3.799 & 3.062 & 3.038 & - & - & - & - \\
\hline Present study & $3.2[2.7-$ & $3.2[2.7$ & 4.0 & $4.0[3.8$ & $8.3[8.0-$ & $8.3[8.1$ & $5.6[5.4-$ & $5.6[5.4$ \\
\hline (Median [IQR]) & 3.3] & $3.3]$ & $4.1]$ & $4.1]$ & 8.5] & 8.5] & 5.8 & $5.7]$ \\
\hline
\end{tabular}




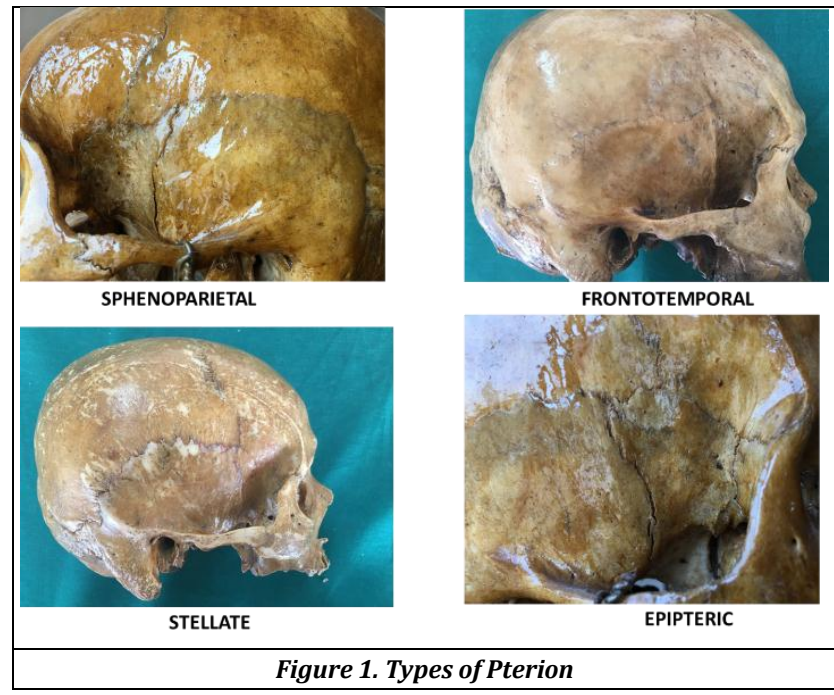

\section{DISCUSSION}

Pterion is used as a landmark in neurosurgeries especially for draining extradural haematomas for optic nerve decompressions and tumour resections. Thus, detailed knowledge of anatomy of pterion and its distance from important landmarks is necessary to avoid complications of surgery. At birth and during fetal life pterion form large membranous areas called anterolateral fontanelles. It provides space for the skull bones to overlap while passing through the birth canal..6]

\section{Types of Pterion}

The four types are sphenoparietal, frontotemporal, stellate and epipteric. In sphenoparietal type is a sutural pattern in which the sphenoid and parietal bones are in direct contact. On the contrary frontotemporal type is in which the frontal and temporal bones are in direct contact. In the stellate type articulation of four bones is seen at a point. A sutural bone if present at the pterion is called as the pterion ossicle or epipteric bone or flower's bone.[12]

In the present study we found sphenoparietal to be commonest on both sides (72\%) followed by frontotemporal $18 \%$, stellate $8 \%$ and epipteric $2 \%$. This was similar to study by Mwachaka et al[13] where they found sphenoparietal variety to be commonest $66.7 \%, 15.5 \%$ frontotemporal, $11.1 \%$ stellate and $6.7 \%$ epipteric.

Sowmya et al[14] found similar results to ours with sphenoparietal $(71.42 \%)$ as commonest followed by frontotemporal (9.35\%). Although in their study epipteric variety $(11.3 \%)$ was more common than stellate $(6.88 \%)$ Study by Adejuwon et al[15] in Nigerian population too found sphenoparietal (86\%) to be commonest but they did not find epipteric variety. Eboh et al.[16] reported $83 \%$ sphenoparietal, $6 \%$ stellate and $6 \%$ epipteric, $5 \%$ frontotemporal type in their study in Nigeria. Matsumura et al.[17] in their study in Japan, have reported $79.1 \%$ sphenoparietal, $17.7 \%$ stellate, $2.6 \%$ frontotemporal, and $0.6 \%$ epipteric type of pterion. Study conducted by Yuvraj et al[18] also found sphenoparietal (75.41\%) to be common. Although the epipteric (13.11\%) variety was common than frontotemporal $(6.55 \%)$ and stellate (4.91\%). This difference between various studies may be explained due to genetic and environmental factors among different populations. A study among 46 dry skulls and 20 cadaveric skulls showed maximum number of epipteric type $21.7 \%$ on right and $26 \%$ on left.[19] In another study most common type of pterion was found to be Sphenoparietal and least incidence was found to be of Frontotemporal (3\%).[20]

Comparison was done among various regions of india with present study. In a study conducted on North Indian population they found most commonly sphenoparietal (86.25\%), followed by fronto temporal (11.25 \%) and stellate (2.5\%).There was no epipteric variety.[21] Study conducted in Western India showed spheno parietal to be most common with $91.27 \%$, followed by fron to temporal $2.4 \%$. $1.2 \%$ was stellate variety and $4.8 \%$ epipteric.[22] There was paucity of study among eastern Indian regions. Authors have speculated reasons behind the greater incidence of sphenoparietal variety. According to Ashley-Montague.[23] sphenoparietal variety of pterion is common in human beings but frontotemporal type is dominant in non-human primates. The development of the calvarium is highly related to the type of brain. This explains the prevalence of frontotemporal pattern of sutures among monkeys who have smaller brains as beings compared to humans with larger brains who have sphenoparietal pattern of suture at pterion.[24] In order to bring about a change from frontotemporal to sphenoparietal type, during evolution, anterosuperior segment of squamous part of temporal bone got detached from it, and got incorporated into the greater wing of sphenoid.

Wang et al, s work on mice models have shown genetic basis for variation of sutural pattern. The gene MSX 2 (on 5q35.2), was found to be responsible for the articulation of cranial bones in pterion. It is a gene of homeobox family involved in cranial suture morphogenesis.[7]

In neurosurgery, to be minimally invasive it is imperative to approach through the most suitable bony aperture.[25] In neurosurgical procedures Pterional approach either alone or in combination with others is the least invasive.[26] In the present study when the results of median [IQR] of distance of centre of pterion to various landmarks was compared on right and left side we did not find any statistical significance. Comparison with other studies are shown in table 3: The Pterional approach is preferable to traditional craniotomy as it involves minor tissue damage, less brain retraction, a superior cosmetic result and shorter duration of surgery.[27]

\section{CONCLUSIONS}

The present study was undertaken to know the distribution of type of pterion and distance of centre of pterion from important landmarks in dry human skulls found in Mangalore. The study showed that spheno-parietal variety to be the commonest (72\%) and least common was epipteric (2\%). On comparison of measurements of right and left sides, distance of centre of pterion from mid-point of superior margin of zygomatic arch (PZA), Frontozygomatic suture (PFZ), tip of the mastoid process (PMP), and anterosuperior margin of external acoustic meatus (PEAM) did not show any significant difference. The knowledge of position of pterion from various landmarks is very important for neurosurgeons as there is chance of injury to vital structures present beneath pterion. This study is aimed at South Indian population and can be conducted among other populations. 


\section{ACKNOWLEDGEMENT}

We thank the Department of Anatomy, K. S. Hegde Medical Academy, medical and dental students for providing us with dry human skulls and instruments for smooth conduction of our study. We sincerely acknowledge the contribution of Dr Ankeeta Menon, Department of Community Medicine, of our college for statistical analysis performed in the study.

\section{REFERENCES}

[1] Moore KL, Dalley AF, Agur AMR. Clinically oriented Anatomy. $6^{\text {th }}$ edn. Baltimore: Lippincott Williams \& Wilkins 2010: p. 828.

[2] Stranding S, Neil RB, Patricia C, et al. Gray's Anatomy: the anatomical basis of clinical practice. $40^{\text {th }}$ edn. Churchill Livingstone Elsevier 2008: p. 403-12.

[3] Quinones-Hinojosa A. Schmidek and Sweet operative neurosurgical techniques - indications, methods and results. Vol. 1. $6^{\text {th }}$ edn. Philadelphia: Elsevier Saunders 2012: p. 609-11.

[4] Lang J. The pterion region and its clinically important distance to the optic nerve. 2. Pterion region, distance to the optic nerve, Dimensions and shape of the recess or the temporal pole. Neurochirurgia (Stuttg) 1984;27 (2):31-5.

[5] Broca P. Instructions craniologiques et craniométriques. Mém Soc Anthrop Paris 1875;2:1-203.

[6] Murphy T. The pterion in the Australian aborigine. Am J Phys Anthropol 1956;14(2):225-44.

[7] Wang Q, Opperman LA, Havill LM, et al. Inheritance of sutural pattern at the pterion in Rhesus monkey skulls. Anat Rec A Discov Mol Cell Evol Biol 2006;288(10):10429.

[8] Prasad H, Bezbaruaz NK, Mishra A, et al. Morphometric analysis of pterion: a clinical anatomical study in North Indian dry skulls. Innovative Journal of Medical and Health Science 2015;5(5):201-5.

[9] Oguz O, Sanli SG, Bozkir MG, et al. The pterion in Turkish male skulls. Surg Radiol Anat 2004;26(3):220-4.

[10] Anjana S, Satheesha KS, Bhaskar R, et al. Morphometric study of pterion in adult dry skulls in Dakshina Kannada district, Karnataka State, India. Int J Anat \& Res 2015;3(4):1603-06.

[11] Sucharitha A, Roshni B. Study of anatomic position of Pterion in dry human skulls in Karnataka. Sch J App Med Sci 2016;4(9B):3272-6.

[12] Williams LP, Bannister LH, Berry MM, et al. Gray's anatomy. 38th $\mathrm{edn}$. London: Churchill Livingstone 1998: $\mathrm{p}$. $568,595$.
[13] Mwachaka PM, Hassanali J, Odula P. Sutural morphology of the pterion and asterion among adult Kenyans. Braz J Morphol Sci 2009;26(1):4-7.

[14] Sowmya S, Meenakshi B, Ranganath P. Study of pterion: Its clinical and morphological aspects. Indian Journal of Clinical Anatomy and Physiology 2017;4(2):247-9.

[15] Adejuwon SA, Olopade FE, Bolaji M. Study of location and morphology of pterion in adult Nigerian skulls. Article ID 403937, ISRN Anatomy 2013;2013:1-4.

[16] Eboh DEO, Obaroefe M. Morphometric study of pterion in dry human skull bones of Nigerians. Int J Morphol 2014;32(1):208-13.

[17] Matsumura G, Kida K, Ichikawa R, et al. Pterion and epipteric bones in Japanese adults and fetuses, with special reference to their formation and variations. Kaibogaku Zasshi 1991;66(5):462-71.

[18] Yuvaraj M, Pushkaran J, Sankaran PK, et al. A morphometric study on different shapes of pterion and its clinical significance. Int J Pharm Bio Sci 2017;8(2):9991003.

[19] Gupta R, Sinha MB, Aggarwal A, et al. Landmarks for keyhole neurosurgical procedures through pterion. Int $\mathrm{J}$ of Healthcare and Biomedical Research 2014;2(4):16875.

[20] Praba AMA, Venkatramaniah C. Morphometric study of different types of pterion and its relation with middle meningeal artery in dry skulls of Tamil Nadu. JPBMS 2012,21(21):1-4.

[21] Suchit K, Shashi MA, Puja C, et al. Pterion its location and clinical implications - a study compared. Journal of Evolution of Medical and Dental Sciences 2013;12(25):4599-608.

[22] Zalawadia A, Vadgama J, Ruparelia S, et al. Morphometric study of pterion in dry skull of Gujarat region. NJIRM 2010;1(4):25-9.

[23] Ashley-Montagu MF. The anthropological significance of the pterion in the primates. American Journal of Physical Anthropology 1933;18(2):159-336.

[24] Saheb SH, Mavishetter GF, Thomas ST, et al. A study of sutural morphology of the pterion and asterion among adult Indian skulls. Biomed Res 2011;22(4):73-5.

[25] Ersoy M, Evliyaoglu C, Bozkurt MC, et al. Epipteric bones in the pterion may be a surgical pitfall. Minim Invasive Neurosurg 2003;46(6):363-5

[26] Urzì F, Iannello A, Torrisi A, et al. Morphological variability of pterion in the human skull. Ital J Anat Embryol 2003;108(2):83-117.

[27] Cheng WY, Lee HT, Sun MH, et al. A pterion keyhole approach for the treatment of anterior circulation aneurysms. Minim Invasive Neurosurg 2006;49(5):25762. 